\title{
A New Mechanism of Acid Rain Generation from HOSO at the Air- Water Interface
}

\author{
Manuel F. Ruiz-López, ${ }^{[\mathrm{a}],{ }^{*}}$ Marilia T. C. Martins-Costa, ${ }^{[a]}{ }^{\mathrm{a}}$ osep M. Anglada ${ }^{[\mathrm{b}]}$ and Joseph S. Fran- \\ $\operatorname{cisco}^{[\mathrm{c}]}$ \\ a] Laboratoire de Physique et Chimie Théoriques, UMR CNRS 7019, University of Lorraine, CNRS, BP 70239, 54506 Van- \\ doeuvre-lès-Nancy, France
}

[b] Departament de Química Biològica (IQAC), CSIC, c/ Jordi Girona 18, E-08034 Barcelona, Spain

[c] Department of Earth and Environmental Science and Department of Chemistry, University of Pennsylvania, Philadelphia, PA, USA 19104-6316

\section{Supporting Information Placeholder}

\begin{abstract}
The photochemistry of $\mathrm{SO}_{2}$ at the air-water interface of water droplets leads to the formation of HOSO radical. Using first-principles simulations, we show that HOSO displays an unforeseen strong acidity $\left(\mathrm{pK}_{\mathrm{a}}=-1\right)$ comparable with nitric acid, and is fully dissociated at the air-water interface. Accordingly, this radical might play an important role in acid rain formation. Potential implications are discussed.
\end{abstract}

The two major acid rain components are $\mathrm{H}_{2} \mathrm{SO}_{4}$ and $\mathrm{HNO}_{3} . \mathrm{SO}_{2}$ is the main precursor of $\mathrm{H}_{2} \mathrm{SO}_{4}$ and oxidation of $\mathrm{S}(\mathrm{IV})$ to $\mathrm{S}(\mathrm{VI})$ can take place in the gas phase or in the aqueous phase. ${ }^{1-2}$ Gas-phase oxidation of $\mathrm{SO}_{2}$ is at the origin of new particle formation mechanisms. Reaction of $\mathrm{SO}_{2}$ with $\mathrm{OH}$ and $\mathrm{O}_{2}$ leads to $\mathrm{SO}_{3}$, which then reacts with water or water dimer ${ }^{3}$ to form sulfuric acid. The high hygroscopicity of $\mathrm{H}_{2} \mathrm{SO}_{4}$ favors the formation of small water clusters that grow by condensation of further water molecules, possibly promoted by ammonia or small amines. ${ }^{4-5}$

Aqueous-phase oxidation of $\mathrm{SO}_{2}$ is, however, the most important pathway to sulfate on a global scale, and the process is even considered as the most important chemical transformation in cloud water. ${ }^{1,6}$ Nevertheless, despite numerous theoretical and experimental studies, $\mathrm{SO}_{2}$ oxidation mechanisms are not yet fully understood. The process is believed to start by uptake of $\mathrm{SO}_{2}$ in water followed by fast ionization: ${ }^{7}$

$$
\begin{aligned}
& \mathrm{SO}_{2} \cdot \mathrm{H}_{2} \mathrm{O} \leftrightarrows \mathrm{H}^{+}+\mathrm{HSO}_{3}^{-} \\
& \mathrm{HSO}_{3}^{-} \leftrightarrows \mathrm{H}^{+}+\mathrm{SO}_{3}^{2-}
\end{aligned}
$$

The $\mathrm{pK}_{\mathrm{a}}$ of aqueous $\mathrm{SO}_{2}$ is $1.86 .{ }^{8}$ In equations 1-2 (and below), the proton is notated $\mathrm{H}^{+}$for simplicity though the relevant species in water is $\mathrm{H}_{3} \mathrm{O}^{+}$. The equilibrium formally involves $\mathrm{H}_{2} \mathrm{SO}_{3}$ but this species has never been isolated and calculations showed that it corresponds to a loosely bonded complex $\mathrm{SO}_{2}\left(\mathrm{H}_{2} \mathrm{O}\right){ }^{9}$ The main species at usual atmospheric $\mathrm{pH}(\mathrm{pH}=2-7)$ is $\mathrm{HSO}_{3}^{-}$. Transformation of S(IV) to S(VI) is facilitated by oxidants such as $\mathrm{O}_{3}, \mathrm{O}_{2}$ (uncatalyzed or catalyzed by transition metal ions), $\mathrm{OH}$ or $\mathrm{HO}_{2}$, but reaction with $\mathrm{H}_{2} \mathrm{O}_{2}$ is particularly efficient because it readily reacts with $\mathrm{HSO}_{3}{ }^{-}$and its concentration is relatively high. ${ }^{2,6}$ The reaction leads to $\mathrm{SO}_{2} \mathrm{OOH}^{-}$, which in acid media finally forms sulfuric acid: ${ }^{1}$

$$
\begin{aligned}
& \mathrm{HSO}_{3}^{-}+\mathrm{H}_{2} \mathrm{O}_{2} \leftrightarrows \mathrm{SO}_{2} \mathrm{OOH}^{-}+\mathrm{H}_{2} \mathrm{O} \\
& \mathrm{SO}_{2} \mathrm{OOH}^{-}+\mathrm{H}^{+} \rightarrow \mathrm{H}_{2} \mathrm{SO}_{4}
\end{aligned}
$$

According to ab initio calculations in water clusters, ${ }^{9-}$ ${ }^{11}$ hydrolysis of $\mathrm{SO}_{2}$ is a thermodynamically unfavorable process with high activation barrier. ${ }^{12}$ Water-assistance may decrease the barrier ${ }^{13}$ but ab initio Molecular Dynamics simulations of $\mathrm{SO}_{2}$ in liquid water could not detect the formation of hydrolyzed species at the timescale of the simulation. ${ }^{14}$ Theoretical studies ${ }^{9-12}$ are consistent with pump-probe experiments on $\mathrm{SO}_{2}\left(\mathrm{H}_{2} \mathrm{O}\right)_{n}$ clusters $(n=1-5)$, which suggested that formation of $\mathrm{HSO}_{3}{ }^{-}$ions is a slow process. ${ }^{15}$

Other experiments have argued that key steps in atmospheric $\mathrm{SO}_{2}$ hydrolysis and oxidation occur at the surface of liquid water, ${ }^{16-18}$ ice $^{10,19-20}$ or dust, ${ }^{21}$ trying to explain why simulations of homogeneous reactions typically underestimate sulfate production. Indeed, experiments ${ }^{17}$ and calculations ${ }^{22}$ have demonstrated that $\mathrm{SO}_{2}$ adsorption at the air-water interface is thermodynamically favorable $\left(\Delta \mathrm{G}_{\mathrm{ads}} \sim 5 \mathrm{kcal} \cdot \mathrm{mol}^{-1}\right)$. Mass-accommodation coefficient measurements in water droplets $^{16}$ concluded that an interfacial contact ion pair is formed, which might be $\mathrm{HSO}_{3}-\mathrm{H}^{+}$. This result was confirmed by 
second-harmonic generation ${ }^{17}$ and vibrational sum-frequency spectroscopy. ${ }^{18}$ Electrospray-ionization mass spectrometry studies of $\mathrm{SO}_{2}$ oxidation at the surface of microdroplets ${ }^{23-24}$ reported four major ions, $\mathrm{HSO}_{3}{ }^{-}$, $\mathrm{SO}_{3}^{-}, \mathrm{SO}_{4}^{-}$and $\mathrm{HSO}_{4}^{-}$at acidic $\mathrm{pH}$ without addition of oxidants other than oxygen. Some experiments have been carried out on ice surface too. FTIR spectroscopy of $\mathrm{SO}_{2}$ on the surface of ice nanoparticles displayed a band that was assigned to $\mathrm{HSO}_{3}{ }^{-19}$ Reactive-ion scattering and low-energy sputtering techniques in conjunction with temperature-programmed desorption mass spectrometry of $\mathrm{SO}_{2}$ on ice films showed that charged molecular species were formed with very low or negligible activation barriers, ${ }^{20}$ and both $\mathrm{SO}_{2}{ }^{-}$and $\mathrm{HSO}_{3}{ }^{-}$anions were identified. ${ }^{10}$

In this communication, we show that $\mathrm{SO}_{2}$ hydrolysis at the water surface may take place photochemically through a process in which S(IV) sulfur dioxide is reduced to S(III) sulfur dioxide radical anion, whose oxidation to bisulfite and bisulfate completes the acid rain formation mechanism. Our study has been carried out using different theoretical methods described in the SI, in particular, Molecular Dynamics (MD) simulations with state-of-the-art quantum-classical (QM/MM) force-fields.

The initial step is the formation of a HOSO radical through reaction of the lowest $\mathrm{SO}_{2}$ triplet $\left({ }^{3} \mathrm{~B}_{1}\right)$ with water. The reaction has recently been observed in gasphase experiments ${ }^{25-26}$ and described through calculations in gas phase $\mathrm{e}^{26-27}$ and at the air-water interface. ${ }^{22,27}$ The long-living ${ }^{3} \mathrm{SO}_{2}$ state is reached either directly from the ground state or (most probably) by intersystem crossing from the lowest excited singlet states $\left({ }^{\mathrm{l}} \mathrm{A}_{2}\right.$ and ${ }^{1} B_{1}$ ) within an absorption band extending between 240 $\mathrm{nm}$ and $330 \mathrm{~nm}^{22,26}$

$$
\begin{aligned}
& \mathrm{SO}_{2}+h v \rightarrow{ }^{1} \mathrm{SO}_{2} \\
& \mathrm{SO}_{2}+h v \rightarrow{ }^{3} \mathrm{SO}_{2} \\
& { }^{1} \mathrm{SO}_{2} \stackrel{I S C}{\rightarrow}{ }^{3} \mathrm{SO}_{2} \\
& { }^{3} \mathrm{SO}_{2}+\mathrm{H}_{2} \mathrm{O} \rightarrow \mathrm{OH}+\mathrm{HOSO}
\end{aligned}
$$

In process (8), $\mathrm{S}(\mathrm{IV})$ is reduced to $\mathrm{S}(\mathrm{III})$, an unusual sulfur oxidation state in the atmosphere, and water is oxidized, making this reaction a potential new source of $\mathrm{OH}$ radicals, as first suggested by Kroll et al. ${ }^{26}$ The reaction could have implications for the formation of $\mathrm{OH}$ in volcanic plumes and in planetary atmospheres deficient in oxygen or ozone. ${ }^{26}$ Estimation of $\mathrm{OH}$ production rates led to the conclusion that the impact of the reaction at the surface of water droplets in the Earth's troposphere could be significant. ${ }^{22}$ Further work has confirmed that the reaction mechanism involves a protoncoupled-electron-transfer mechanism that is favored by water solvation, so that the activation free energy at the air-water interface is predicted to be low $\left(<1 \mathrm{kcal} \cdot \mathrm{mol}^{-1}\right.$ at $298 \mathrm{~K}$ ) and the triplet is predicted to be rapidly hydrolyzed. ${ }^{27}$ The atmospheric chemistry of HOSO is poorly known though some studies in gas phase have been reported. $^{22,26,28-40}$

The outcome of HOSO following (8) is unknown despite the atmospheric relevance of related species such as HONO. ${ }^{1}$ To get insights into HOSO chemistry at the air-water interface, QM/MM MD simulations have been carried out in which HOSO and one water molecule are described quantum mechanically $(\mathrm{B} 3 \mathrm{LYP} / 6-311+\mathrm{G}(\mathrm{d})$ level ${ }^{41}$ ), while the rest of water molecules are described classically (TIP3 $\mathrm{P}^{42}$ force field). We found that the radical undergoes spontaneous ionization through proton transfer to $\mathrm{H}_{2} \mathrm{O}$ (Figure 1) after less than 30 ps of production run. The proton transfer itself occurs in a very short time-scale (few tens of femtosecond) characteristic of strongly hydrogen-bonded systems. ${ }^{43}$ Figure 2 displays some snapshots along the simulation. Throughout the transfer, HOSO and water approach to each other, the two O-H distances being short and similar ( 1.1-1.2 $\AA$ ), and the incipient ion-pair is stabilized by strong hydrogen-bonds with surrounding classical water molecules.

To get a deeper insight into the ionization mechanism, we have carried out $\mathrm{B} 3 \mathrm{LYP} / 6-311+\mathrm{G}(\mathrm{d})$ calculations in a $\left(\mathrm{H}_{2} \mathrm{O}\right)_{21}$ cluster. $^{44}$ The results confirm the ease of HOSO dissociation, the relative energy between the reactant and final ion-pair complex being $+1.6 \mathrm{kcal} \cdot \mathrm{mol}^{-1}$ (Figure 3). Detailed analysis of the mechanism shows an asynchronous process involving several proton transfers that starts, as in the MD simulation, by a transfer in a closely linked HOSO-water complex (see SI).

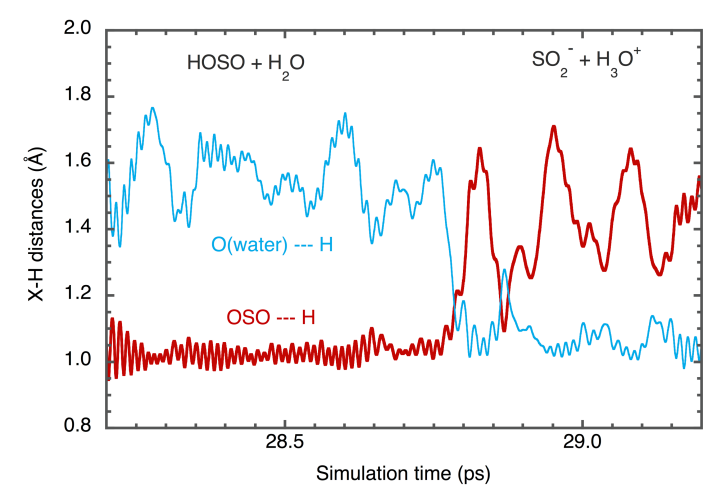

Figure 1. Time evolution of $\mathrm{OH}$ distances in the $\mathrm{H}_{2} \mathrm{O} \cdots \mathrm{HOSO}$ system from QM/MM simulations at the airwater interface. 

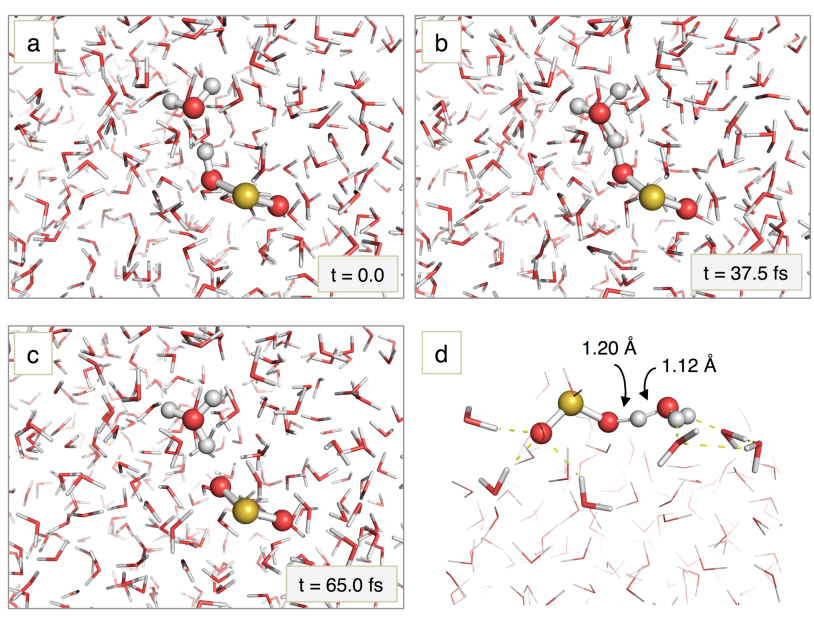

Figure 2. (a-c) Snapshots showing the HOSO ionization process at the air-water interface (top view) and relative time. (d) Detail of HOSO-water QM system and TIP3P solvation shell from snapshot $b$.
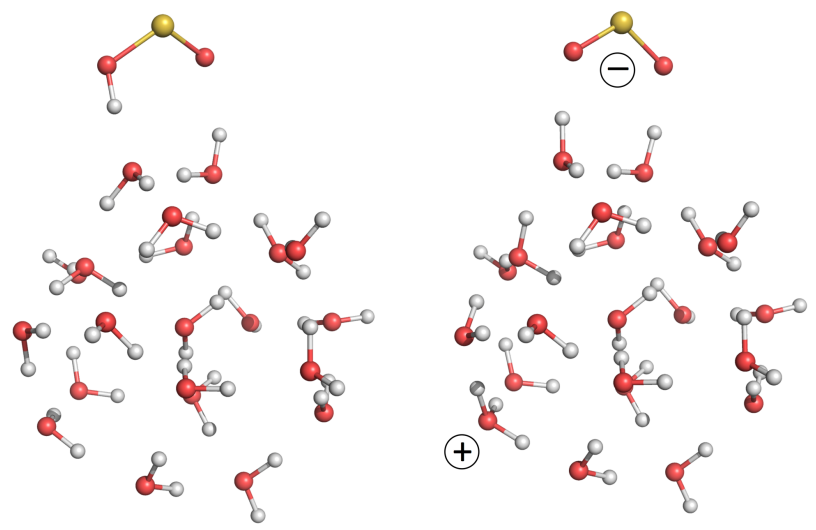

Figure 3. $\mathrm{HOSO}\left(\mathrm{H}_{2} \mathrm{O}\right)_{21}$ and $\left(\mathrm{SO}_{2}^{-}\right)\left(\mathrm{H}_{3} \mathrm{O}^{+}\right)\left(\mathrm{H}_{2} \mathrm{O}\right)_{20}$ structures optimized at B3LYP/6-311+G(d) level.

Whether an acid can dissociate can be assessed by its $\mathrm{pK}_{\mathrm{a}}$ value, with lower $\mathrm{pK}_{\mathrm{a}}$ favoring dissociation. The present simulation indicates that HOSO behaves like a strong acid that dissociates as soon as formed through reaction (8) at the water surface, contributing to acidify the medium. The acidic character of the related species HONO and HOCO is well documented $\left(\mathrm{pK}_{\mathrm{a}}{ }^{\mathrm{HONO}}=\right.$ $3.16^{45}, \mathrm{pK}_{\mathrm{a}}^{\mathrm{HOCO}}=3.4^{46}$ ) but $\mathrm{HOSO}$ acidity in either gas or aqueous phase is unknown. Hence, we have made an estimation through $a b$ initio computations at the CCSD(T)/aug-cc-pVTZ//MP2/aug-cc-pVTZ level of theory using an implicit solvation model. The results for gas phase acidity and $\mathrm{pK}_{\mathrm{a}}$ in water solution are summarized in Table 1. In this Table, we include calculations and experimental data for HONO, for comparison.

The calculated gas phase acidity for HONO is very close to experiment ${ }^{47}$ and to previous calculations. ${ }^{48} \mathrm{Re}-$ markably, the gas phase acidity of HOSO is $\sim 10$ $\mathrm{kcal} \cdot \mathrm{mol}^{-1}$ lower than that of HONO. Analysis of gas phase ionization processes in terms of the thermodynamic cycle in Figure 4 provides some explanation for this finding. The experimental electron affinities of $\mathrm{NO}_{2}$ and $\mathrm{SO}_{2}$ are, respectively, 52.4 and $25.5 \mathrm{kcal} \cdot \mathrm{mol}^{-1}$, 49 and the homolytic bond dissociation energy of HONO $(\mathrm{H}+\mathrm{ONO})$ amounts $78.4 \mathrm{kcal} \cdot \mathrm{mol}^{-1}$ (using reported heats of formation ${ }^{49}$ ). There is no experimental dissociation energy value for HOSO but there are several ab initio calculations reporting similar values. ${ }^{35,39}$ For instance, Grant et al ${ }^{50}$ obtained $39.7 \mathrm{kcal} \cdot \mathrm{mol}^{-1}$. By comparing these quantities, it clearly appears that the greater acidity of HOSO with respect to HONO is due to its much lower $\mathrm{O}-\mathrm{H}$ bond dissociation energy, which is partially compensated by a significantly lower electron affinity of $\mathrm{SO}_{2}$ compared to $\mathrm{NO}_{2}$.

A strong HOSO acidity is also found in liquid water, with $\mathrm{pK}_{\mathrm{a}}=-1$ (see Table 1). This $\mathrm{pK}_{\mathrm{a}}$ value is more than 4 units smaller compared to $\mathrm{HONO}$ and is comparable to the $\mathrm{pK}_{\mathrm{a}}$ of nitric acid $\left(\mathrm{pK}_{\mathrm{a}}=-1.38\right)$. Such a strong acidity explains and corroborates the results obtained in the simulations at the air-water interface (note that effective $\mathrm{pK}_{\mathrm{a}}$ at the interface may be slightly different from bulk). ${ }^{51}$ HOSO is therefore expected to spontaneously and completely dissociate in water.

At this stage, the net photochemical process initiated by the absorption of sunlight by aqueous $\mathrm{SO}_{2}$ can be written as:

$$
\left(\mathrm{SO}_{2}\right)_{\mathrm{aq}}+\left(\mathrm{H}_{2} \mathrm{O}\right)_{\mathrm{aq}}+h v \rightarrow \mathrm{OH}+\mathrm{H}^{+}+\mathrm{SO}_{2}^{-}
$$

which results in the formation of the radical anion $\mathrm{SO}_{2}{ }^{-}$ at the interface. Very interestingly, this anion has been identified in $\mathrm{SO}_{2}$ hydrolysis experiments on ice surfaces, ${ }^{10}$ as mentioned above, and this correlation supports the mechanism studied here. Ascertaining the atmospheric impact of (9) will require further studies, and experiments under $\mathrm{SO}_{2}$ irradiation in the absence of oxidants are appealing. We present here a qualitative analysis based on the present results and previously reported reaction rates.

Since HOSO is much more acidic than $\mathrm{SO}_{2}$, process (9) leads to acidification of the medium, eventually boosted by subsequent oxidation of $\mathrm{SO}_{2}^{-}$to sulfate. A rough estimation of the upper limit for the formation rate of $\mathrm{SO}_{2}{ }^{-}$and $\mathrm{H}^{+}$is (see SI) $0.2 \times 10^{10}$ molecule $\cdot \mathrm{cm}^{-3} \cdot \mathrm{s}^{-}$ ${ }^{1}\left(\mathrm{ppb}\left[\mathrm{SO}_{2}\right]_{\mathrm{gas}}\right)^{-1}$. On the other hand, conventional S(IV) to $\mathrm{S}(\mathrm{VI})$ conversion by usual atmospheric oxidants in the $\mathrm{pH}$ range 3-6 spreads between $10^{8}-10^{13}$ molecule $\cdot \mathrm{cm}^{-3} \cdot \mathrm{s}^{-1}$ (ppb $\left.\left[\mathrm{SO}_{2}\right]_{\mathrm{gas}}\right)^{-1}$, with $\mathrm{H}_{2} \mathrm{O}_{2}$ providing the highest values. ${ }^{1-2}$ Thus, HOSO contribution could become significant for $\mathrm{SO}_{2}$ peaks attaining several hundreds of $\mathrm{ppb}$ and environments depleted in $\mathrm{H}_{2} \mathrm{O}_{2}$.

Moreover, oxidation of $\mathrm{SO}_{2}^{-}$formed in (9) to $\mathrm{S}(\mathrm{VI})$ should also contribute to decrease the $\mathrm{pH}$. Arguably, the atypical radical anions $\mathrm{SO}_{3}^{-}, \mathrm{SO}_{4}{ }^{-}$or $\mathrm{SO}_{5}{ }^{-}$might easily 
be formed from the parent radical $\mathrm{SO}_{2}{ }^{-}$through reactions with common atmospheric oxidants such as $\mathrm{O}_{2}$, $\mathrm{O}_{3}, \mathrm{H}_{2} \mathrm{O}_{2}, \mathrm{OH}$ or $\mathrm{HO}_{2}$. This is a key feature because those species lead to free radical chain reactions that have been shown to be involved in non-catalyzed $\mathrm{SO}_{2}$ oxidation by $\mathrm{O}_{2}$ at the surface of microdroplets and provide a significant contribution to the net sulfate formation in the atmosphere. ${ }^{23-24}$ The process is supposed to be initiated by the sulfite radical anion $\mathrm{SO}_{3}{ }^{-}$but generation of this species remains unclear. ${ }^{24}$ Since $\mathrm{SO}_{2}{ }^{-}$has been detected in flash photolysis studies of these chain reactions,${ }^{52}$ one may infer that photochemistry of $\mathrm{SO}_{2}$ at the air-water interface might also contribute to sulfate formation by triggering the oxidation mechanism by $\mathrm{O}_{2}$.

Note finally that reaction with $\mathrm{OH}$ leads to bisulfite:

$\mathrm{SO}_{2}^{-}+\mathrm{OH} \rightarrow \mathrm{HSO}_{3}^{-}$

so that the overall reaction in that case is equivalent to (1), and that reaction with $\mathrm{HO}_{2}\left(\right.$ or $\left.\mathrm{O}_{2}{ }^{-}\right)$directly leads to $\mathrm{S}(\mathrm{VI})$ in form of bisulfate (11) or sulfate (12):

$$
\begin{aligned}
& \mathrm{SO}_{2}^{-}+\mathrm{OOH} \rightarrow \mathrm{HSO}_{4}^{-} \\
& \mathrm{HSO}_{4}^{-} \leftrightarrows \mathrm{H}^{+}+\mathrm{SO}_{4}^{2-}
\end{aligned}
$$

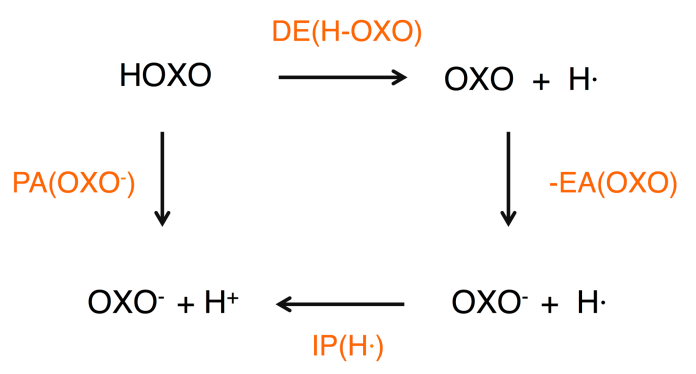

Figure 4. Thermodynamic cycle connecting HOXO ionization with other thermodynamic quantities $(\mathrm{DE}=$ dissociation energy, $\mathrm{EA}=$ electron affinity, $\mathrm{IP}=$ ionization potential, $\mathrm{PA}=$ proton affinity)

Table 1. Calculated gas-phase acidities $\left(\Delta \mathbf{G}_{\mathbf{a}}\right)$, solvation energies $\left(\Delta G_{s}{ }^{Y}\right)$ and $\mathrm{pK}_{\mathrm{a}}$ in water for HONO and HOSO. ${ }^{1}$

\begin{tabular}{l|l|l|l|l|l}
\hline & $\Delta \mathrm{G}_{\mathrm{a}}$ & $\Delta \mathrm{G}_{\mathrm{s}}{ }^{\text {HOXO }}$ & $\Delta \mathrm{G}_{\mathrm{s}}{ }^{\text {OXO- }}$ & $\Delta \mathrm{pK}_{\mathrm{a}}$ & $\mathrm{pK}_{\mathrm{a}}$ \\
\hline HONO & 333.6 & -2.43 & -64.45 & 0.0 & 3.16 \\
& $333.7^{2}$ & & & & $3.16^{3}$ \\
HOSO & 323.2 & -3.60 & -61.10 & -4.16 & -1.0 \\
\hline
\end{tabular}

${ }^{1}$ Calculated $\mathrm{pK}_{\mathrm{a}}$ is given relative to HONO. Energies at $298 \mathrm{~K}$, in $\mathrm{kcal} \cdot \mathrm{mol}^{-1}$ at $\mathrm{CCSD}(\mathrm{T}) / / \mathrm{MP} 2$ level. Experimental values are in italics. ${ }^{2}$ Reference. ${ }^{47}{ }^{3}$ Reference. ${ }^{45}$

In summary, we have shown that the photochemistry of $\mathrm{SO}_{2}$ can be an important ingredient in the overall mechanism of acid rain formation not yet considered by current atmospheric models. The key step in this mechanism is the population of the lowest triplet state, which at the surface of water droplets undergoes a fast redox reaction with water producing $\mathrm{HOSO}$ and $\mathrm{OH}$ radicals. The role of the former in the troposphere is still poorly known but we have shown that HOSO is a strong acid that completely dissociates in aqueous media forming the reactive $\mathrm{S}(\mathrm{III})$ radical anion $\mathrm{SO}_{2}{ }^{-}$. An important finding from this work is that HOSO, the intermediate resulting from the hydrolysis of triplet $\mathrm{SO}_{2}$, can directly contribute to atmospheric acid formation, in addition to the two well-known components: sulfuric acid $\left(\mathrm{H}_{2} \mathrm{SO}_{4}\right)$ and nitric acid $\left(\mathrm{HNO}_{3}\right)$. This finding significantly broadens the atmospheric chemistry of aqueous $\mathrm{SO}_{2}$.

\section{ASSOCIATED CONTENT}

Details on computational methods and calculations are provided as Supporting Information. The Supporting Information is available free of charge on the ACS Publications.

\section{AUTHOR INFORMATION}

\section{Corresponding Author}

Manuel.Ruiz@,univ-lorraine.fr

\section{ORCID}

Manuel F. Ruiz-Loṕez:0000-0002-2784-6319

Marilia T. C. Martins-Costa: 0000-0003-4957-2248

Josep M. Anglada: 0000-0003-4526-3624

Joseph S. Francisco: 0000-0002-5461-1486

Notes

The authors declare no competing financial interest.

\section{ACKNOWLEDGMENT}

MFRL and MTCMC are grateful to the French CINES (project lct2550) for providing computational resources. JMA thanks the Generalitat de Catalunya (Grant 2017SGR348) for financial support.

\section{REFERENCES}

1. Seinfeld, J. H.; Pandis, S. N. Atmospheric Chemistry and Physics: From Air Pollution to Climate Change. 2nd ed.; Wiley: New York, 2006.

2. Calvert, J. G.; Lazrus, A.; Kok, G. L.; Heikes, B. G.; Walega, J. G.; Lind, J.; Cantrell, C. A. Chemical mechanisms of acid generation in the troposphere. Nature 1985, 317, 27-35.

3. Morokuma, K.; Muguruma, C. Ab initio molecular orbital study of the mechanism of the gas phase reaction $\mathrm{SO}_{3}+\mathrm{H}_{2} \mathrm{O}$ : Importance of the second water molecule. J. Am. Chem. Soc. 1994, 116, 10316-10317.

4. Curtius, J. Nucleation of atmospheric aerosol particles. $C$. R. Phys. 2006, 7, 1027-1045.

5. Nieminen, T.; Asmi, A.; Dal Maso, M.; Aalto, P. P.; Keronen, P.; Petäjä, T.; Kulmala, M.; Kerminen, V.-M. Trends in atmospheric new-particle formation: 16 years of observations in a boreal-forest environment. Boreal Env. Res. 2014, 19 (suppl. B), 191-214.

6. Berglen, T. F.; Berntsen, T. K.; Isaksen, I. S.; Sundet, J. K. A global model of the coupled sulfur/oxidant chemistry in the troposphere: The sulfur cycle. J. Geophys. Res.-Atmos. 2004, 109, Art. No. D19310. 
7. $\quad$ Eigen, M.; Kustin, K.; Maass, G. Die Geschwindigkeit der Hydratation von $\mathrm{SO} 2$ in wäßriger Lösung. Z Phys Chem 1961, 30, $130-136$.

8. Goldberg, R. N.; Kishore, N.; Lennen, R. M. Thermodynamic quantities for the ionization reactions of buffers. $J$. Phys. Chem. Ref. Data 2002, 31, 231-370.

9. Bishenden, E.; Donaldson, D. Ab Initio Study of $\mathrm{SO}_{2}+$ $\mathrm{H}_{2}$ O. J. Phys. Chem. A 1998, 102, 4638-4642.

10. Bang, J.; Shoaib, M. A.; Choi, C. H.; Kang, H. Efficient Thermal Reactions of Sulfur Dioxide on Ice Surfaces at Low Temperature: A Combined Experimental and Theoretical Study. ACS Earth Space Chem. 2017, 1, 503-510.

11. Vahedpour, M.; Zolfaghari, F. Mechanistic study on the atmospheric formation of acid rain base on the sulfur dioxide. Struct. Chem. 2011, 22, 1331-1338.

12. Loerting, T.; Kroemer, R. T.; Liedl, K. R. On the competing hydrations of sulfur dioxide and sulfur trioxide in our atmosphere. Chem. Comm. 2000, 999-1000.

13. Liu, J.; Fang, S.; Liu, W.; Wang, M.; Tao, F.-M.; Liu, J.y. Mechanism of the Gaseous Hydrolysis Reaction of $\mathrm{SO}_{2}$ : Effects of $\mathrm{NH}_{3}$ versus $\mathrm{H}_{2}$ O. J. Phys. Chem. A 2015, 119, 102-111.

14. Moin, S. T.; Lim, L. H. V.; Hofer, T. S.; Randolf, B. R.; Rode, B. M. Sulfur Dioxide in Water: Structure and Dynamics Studied by an $\mathrm{Ab}$ Initio Quantum Mechanical Charge Field Molecular Dynamics Simulation. Inorg. Chem. 2011, 50, 3379-3386.

15. Dermota, T.; Hydutsky, D.; Bianco, N.; Castleman, A. Ultrafast Dynamics of the $\mathrm{SO}_{2}\left(\mathrm{H}_{2} \mathrm{O}\right)_{\mathrm{n}}$ Cluster System. J. Phys. Chem. A 2005, 109, 8254-8258.

16. Jayne, J. T.; Davidovits, P.; Worsnop, D. R.; Zahniser, M. $\mathrm{S}$; Kolb, C. E. Uptake of $\mathrm{SO}_{2}(\mathrm{~g})$ by aqueous surfaces as a function of $\mathrm{pH}$ - the effect of chemical-reaction at the interface. J. Phys. Chem. 1990, 94, 6041-6048.

17. Donaldson, D.; Guest, J. A.; Goh, M. C. Evidence for adsorbed $\mathrm{SO}_{2}$ at the aqueous-air interface. J. Phys. Chem. 1995, 99, 9313-9315

18. Tarbuck, T. L.; Richmond, G. L. Adsorption and Reaction of $\mathrm{CO}_{2}$ and $\mathrm{SO}_{2}$ at a Water Surface. J. Am. Chem. Soc. 2006, 128, 3256-3267.

19. Jagoda-Cwiklik, B.; Devlin, J.; Buch, V. Spectroscopic and computational evidence for $\mathrm{SO}_{2}$ ionization on $128 \mathrm{~K}$ ice surface. Phys. Chem. Chem. Phys. 2008, 10, 4678-4684.

20. Kim, Y.-K.; Kim, S.-K.; Kim, J.-H.; Kang, H. Kinetic isolation of reaction intermediates on ice surfaces. Precursor states of $\mathrm{SO}_{2}$ hydrolysis. J. Phys. Chem. C. 2009, 113, 16863-16865.

21. Yun, J.; Zhu, C.; Wang, Q.; Hu, Q.; Yang, G. Catalytic conversions of atmospheric sulfur dioxide and formation of acid rain over mineral dusts: Molecular oxygen as the oxygen source. Chemosphere 2019, 217, 18-25.

22. Martins-Costa, M. T.; Anglada, J. M.; Francisco, J. S.; Ruiz-López, M. F. Photochemistry of $\mathrm{SO}_{2}$ at the Air-Water Interface: A Source of OH and HOSO Radicals. J. Am. Chem. Soc. 2018, 140, 12341-12344.

23. Hung, H. M.; Hoffmann, M. R. Oxidation of Gas-Phase $\mathrm{SO}_{2}$ on the Surfaces of Acidic Microdroplets: Implications for Sulfate and Sulfate Radical Anion Formation in the Atmospheric Liquid Phase. Environ. Sci. Technol. 2015, 49, 13768-13776.

24. Hung, H. M.; Hsu, M. N.; Hoffmann, M. R. Quantification of $\mathrm{SO}_{2}$ Oxidation on Interfacial Surfaces of Acidic Micro-Droplets: Implication for Ambient Sulfate Formation. Environ. Sci. Technol. 2018, 52, 9079-9086.

25. Donaldson, D. J.; Kroll, J. A.; Vaida, V. Gas-phase hydrolysis of triplet $\mathrm{SO}_{2}$ : A possible direct route to atmospheric acid formation. Scientific reports 2016, 6, Art. No. 30000.

26. Kroll, J. A.; Frandsen, B. N.; Kjaergaard, H. G.; Vaida, V. Atmospheric Hydroxyl Radical Source: Reaction of Triplet $\mathrm{SO}_{2}$ and Water. J. Phys. Chem. A 2018, 122, 4465-4469.

27. Anglada, J. M.; Martins-Costa, M. T. C.; Francisco, J. S.; Ruiz-López, M. F. Triplet state promoted reaction of $\mathrm{SO}_{2}$ with $\mathrm{H}_{2} \mathrm{O}$ by competition between proton coupled electron transfer (pcet) and hydrogen atom transfer (hat) processes. Phys. Chem. Chem. Phys. 2019, 21, 9779-9784.
28. Fortenberry, R. C.; Francisco, J. S.; Leel, T. J. Quantum Chemical Rovibrational Analysis of the HOSO Radical. J. Phys. Chem. A 2017, 121, 8108-8114.

29. Lesar, A.; Tavcar, A. Atmospheric Reaction of the HOSO Radical with $\mathrm{NO}_{2}$ : A Theoretical Study. J. Phys. Chem. A 2011, 115, 11008-11015.

30. Lesar, A.; Tusar, S. Structure, Stability, and Spectroscopic Properties of H-Bonded Complexes of $\mathrm{HOSO}$ and $\mathrm{CH}_{3} \mathrm{SO}$ with $\mathrm{H}_{2} \mathrm{O}$. J. Phys. Chem. A 2014, 118, 7855-7862.

31. Lesar, A.; Tusar, S. Water mediated hydrogen abstraction mechanism in the radical reaction between $\mathrm{HOSO}$ and $\mathrm{NO}_{2}$. Chem. Phys. Lett. 2016, 651, 209-215.

32. Sun, Y. Q.; Wang, X.; Bai, F. Y.; Pan, X. M. Theoretical study of the hydrolysis of $\mathrm{HOSO}+\mathrm{NO}_{2}$ as a source of atmospheric HONO: effects of $\mathrm{H}_{2} \mathrm{O}$ or $\mathrm{NH}_{3}$. Environmental Chemistry 2017, 14, 19-30.

33. Sugimoto, H.; Tachikawa, M.; Udagawa, T. Multicomponent QM study on the reaction of $\mathrm{HOSO}+\mathrm{NO}_{2}$ with $\mathrm{H}_{2} \mathrm{O}$ : Nuclear quantum effect on structure and reaction energy profile. Int. J. Quantum Chem. 2019, 119, Art. No. e25895.

34. Rodríguez-Linares, D.; Freitas, G. N.; Ballester, M. Y.; Nascimento, M. A. C.; Garrido, J. D. Coupled-Cluster Study of the Lower Energy Region of the Ground Electronic State of the $\mathrm{HSO}_{2}$ Potential Energy Surface. J. Phys. Chem. A 2015, 119, 8734-8743.

35. Wheeler, S. E.; Schaefer, H. F. Thermochemistry of the HOSO Radical, a Key Intermediate in Fossil Fuel Combustion. J. Phys. Chem. A 2009, 113, 6779-6788.

36. McCarthy, M. C.; Lattanzi, V.; Martinez Jr, O.; Gauss, J. r.; Thorwirth, S. Spectroscopic detection and structure of hydroxidooxidosulfur (HOSO) radical, an important intermediate in the chemistry of sulfur-bearing compounds. J. Phys. Chem. Lett. 2013, 4, 4074-4079.

37. McKee, M. L.; Wine, P. Ab initio study of the atmospheric oxidation of $\mathrm{CS}_{2}$. J. Am. Chem. Soc. 2001, 123, 2344-2353.

38. Rasmussen, C. L.; Glarborg, P.; Marshall, P. Mechanisms of radical removal by $\mathrm{SO}_{2}$. Proc. Combust. Inst. 2007, 31, 339-347.

39. Ballester, M. Y.; Varandas, A. J. C. Double many-body expansion potential energy surface for ground state $\mathrm{HSO}_{2}$. Phys Chem. Chem. Phys. 2005, 7, 2305-2317.

40. Ballester, M. Y.; Varandas, A. J. C. Theoretical study of the reaction $\mathrm{OH}+\mathrm{SO} \rightarrow \mathrm{H}+\mathrm{SO}_{2}$. Chem. Phys. Lett. 2007, 433, 279285.

41. Becke, A. D. Density-Functional thermochemistry. iii. The role of exact exchange. J. Chem. Phys. 1993, 98, 5648-5652.

42. Jorgensen, W. L.; Chandrashekar, J.; Madura, J. D.; Impey, W. R.; Klein, M. L. Comparison of simple potential functions for simulating liquid water. J. Chem. Phys. 1983, 79, 926-935.

43. Tuñón, I.; Martins-Costa, M. T. C.; Millot, C.; RuizLópez, M. F. Molecular dynamics simulations of elementary chemical processes in liquid water using combined density functional and molecular mechanics potentials. I. Proton transfer in strongly $\mathrm{H}-$ bonded complexes. J. Chem. Phys. 1997, 106, 3633-3642.

44. Torrent-Sucarrat, M.; Ruiz-Lopez, M. F.; Martins-Costa, M.; Francisco, J. S.; Anglada, J. M. Protonation of water clusters induced by hydroperoxyl radical surface adsorption. Chem. Eur. J. 2011, 17, 5076-5085.

45. Da Silva, G.; Kennedy, E. M.; Dlugogorski, B. Z. Ab initio procedure for aqueous-phase $\mathrm{pK}_{\mathrm{a}}$ calculation: the acidity of nitrous acid. J. Phys. Chem. A 2006, 110, 11371-11376.

46. Janik, I.; Tripathi, G. N. R. The nature of the $\mathrm{CO}_{2}$-radical anion in water. J. Chem. Phys. 2016, 144, Art. No. 154307.

47. Roberts, J. M.; Veres, P.; Warneke, C.; Neuman, J.; Washenfelder, R.; Brown, S.; Baasandorj, M.; Burkholder, J.; Burling, I.; Johnson, T. J. Measurement of HONO, HNCO, and other inorganic acids by negative-ion proton-transfer chemical-ionization mass spectrometry (NI-PT-CIMS): Application to biomass burning emissions. Atmospheric Meas. Tech. 2010, 3, 981-990.

48. Dixon, D. A.; Feller, D.; Zhan, C. G.; Francisco, J. S. The gas and solution phase acidities of HNO, HOONO, HONO, and $\mathrm{HONO}_{2}$. Int. J. Mass Spectrom. 2003, 227, 421-438. 
49. Nist Chemical Kinetics Database. http://kinetics.nist.gov/kinetics/index.jsp (accessed July 2019).

50. Grant, D. J.; Dixon, D. A.; Francisco, J. S.; Feller, D.; Peterson, K. A. Heats of Formation of the $\mathrm{H}_{1,2} \mathrm{O}_{\mathrm{m}} \mathrm{S}_{\mathrm{n}}(\mathrm{m}, \mathrm{n}=0-3)$ Molecules from Electronic Structure Calculations. J. Phys. Chem. A 2009, 113, 11343-11353.

51. Martins-Costa, M. T. C.; Anglada, J. M.; Francisco, J. S.; Ruiz-Lopez, M. Reactivity of Atmospherically Relevant Small
Radicals at the Air-Water Interface. Angew. Chem. Int. Ed. 2012, 51, $5413-5417$.

52. Hayon, E.; Treinin, A.; Wilf, J. Electronic spectra, photochemistry, and autoxidation mechanism of the sulfite-bisulfitepyrosulfite systems. $\mathrm{SO}_{2}^{-}, \mathrm{SO}_{3}{ }^{-}, \mathrm{SO}_{4}^{-}$, and $\mathrm{SO}_{5}^{-}$radicals. J. Am. Chem. Soc. 1972, 94, 47-57. 
Insert Table of Contents artwork here

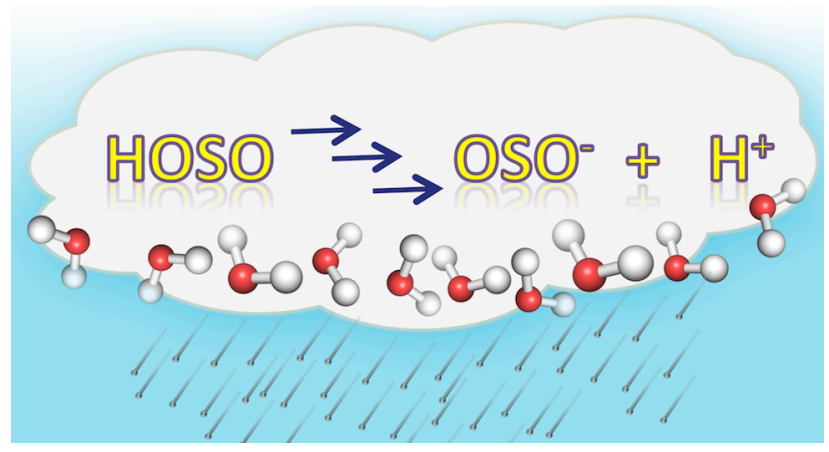

